\title{
Desarrollo humano y calidad de vida en Latinoamérica: Espacio público y ciudadanía en perspectiva ética
}

HUMAN DEVELOPMENT AND QUALITY OF LIFE IN

LATIN AMERICA: PUBLIC

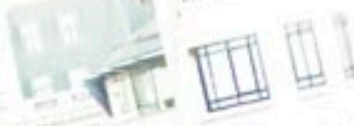

$-032$

Bioética

\section{DÁlvaro Andrés Hamburger Fernández"}

SPACE AND CITIZENSHIP IN

ETHICAL PERSPECTIVE

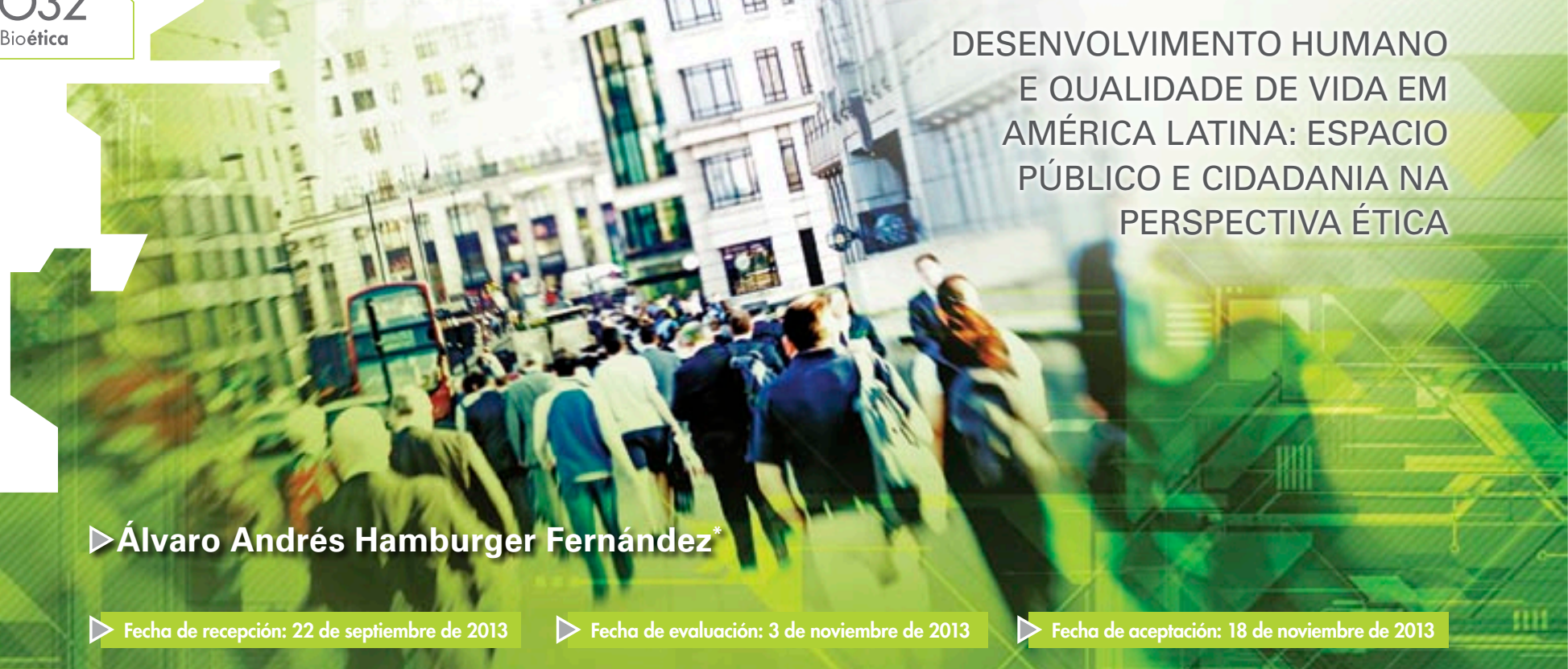

$\triangle$ Fecha de recepción: 22 de sepliembre de 2013

$\triangle$ Fecha de evaluación: 3 de noviembre de 2013

Fecha de aceplacion. 18 de novientore de 2013

Magíster en Filosofía Latinoamericana de la Universidad Santo Tomás, Bogotá; Doctorante en Procesos Sociales y Políticos de América Latina de la Universidad de Arte y Ciencias Sociales de Santiago de Chile (U-ARCIS). Editor de Gestión \& Sociedad, revista de la Facultad de Ciencias Administrativas y Contables de la Universidad de La Salle, Bogotá. Profesor invitado del Instituto de Postgrados-Forum de la Universidad de La Sabana, Bogotá. 
El desarrollo humano y la calidad de vida de una sociedad se manifiestan de muchas maneras. Sin embargo, estos aspectos siempre están asociados a la plena realización y expresión de la vida comunitaria, de la vida en sociedad y, en tal medida, se hacen evidentes en la concreción de valores tales como la inclusión, la participación, la solidaridad y la equidad. En tal sentido, en este artículo se define y caracteriza la ética cívica y se la propone como un espacio de reflexión y de acción a partir del cual es posible reconstruir y expresar más adecuadamente las categorías de espacio público y ciudadanía en Latinoamérica. Como sabemos, históricamente nuestra región se ha caracterizado por presentar altos niveles de exclusión de los sectores populares en todo lo que atañe a la vida política, económica y social; situación que ha llevado a que un gran porcentaje de la población (especialmente originarios, afros y mujeres) no haya podido acceder apropiada ni suficientemente a los beneficios de la ciudadanía y de la democracia como expresiones de lo público. De esta manera, en este escrito se afirma que la ética cívica contiene los referentes teórico-prácticos que harían posible la reordenación y la reconfiguración de la sociedad latinoamericana, de tal suerte que los valores inherentes a la vida comunitaria garanticen la convivencia y el equilibrio propios de las culturas auténticamente democráticas y humanamente desarrolladas.

Palabras Clave

Ética cívica, inclusión, equidad, democracia, participación.

\section{SUMMARY}

Human development and the quality of life of a society are manifested in many ways. However, these aspects will always be associated with the full realization and expression of community life, social life and this way will become apparent in the realization of values like inclusion, participation, solidarity and equity. This article defines and characterizes civic ethics and proposes this as a space for reflection and action from which it is possible to reconstruct and express more adequately the categories of public space and citizenship in Latin America. As we know, our region has historically characterized by having high levels of exclusion of the popular sectors in all matters pertaining to the political, economic and social life, and this situation has led a large percentage of the population (especially originating, African Americans and women) have not been appropriate or sufficient accessed to the benefits of citizenship and democracy as expressions of the public issues. Thus, this text states that civic ethics contains theoretical and practical references that would make possible the reorganization and reconfiguration of Latin American society, so that the values inherent to community life ensure coexistence and balance of truly democratic and humanly developed cultures.

In accordance with the statements, it first analyzes the contemporary theoretical debate on public space and citizenship and its impact on the configuration of Latin American societies, then civic ethics is presented as a viable alternative that can contribute decisively and effectively to achieving this configuration.

\section{Keywords}

Civic ethics, inclusion, equity, democracy, participation.

\section{RESUMO}

O desenvolvimento humano e qualidade de vida de uma sociedade se manifestam de várias maneiras. No entanto, esses aspectos sempre serán associados com a plena realização e expressão da vida comunitária, da vida em sociedade e em que medida será evidente na realização de valores como inclusão, participação, solidariedade e equidade.

Neste artigo é definida e caracterizada a ética cívica e pretende este como um espaço de reflexão e ação a partir do qual é possível reconstruir e expressar mais adequadamente as categorias de espaço público e cidadania na América Latina. Como sabemos, historicamente nossa região tem sido caracterizada por altos níveis de exclusão dos setores populares de todas as coisas relacionadas à vida política, económica e social; esta situação tornou-se que uma grande porcentagem da população (especialmente indígenas, negros e mulheres) não ter sido capaz de acesso apropriado nem suficiente aos benefícios da cidadania e da democracia como expressões do público. Assim, este texto afirma que a ética cívica contém as referências teóricas e práticas que tornaria possível a reorganização e a reconfiguração da sociedade latino-americana, de tal forma que os valores inerentes à vida em comunidade asseguram a coexistência e equilíbrio das culturas genuinamente democráticas e humanamente desenvolvidas.

De acordo com isso, em primeira instância é analisado o debate teórico contemporâneo sobre espaço público e cidadania e seu impacto sobre a configuração das sociedades latino-americanas; então é apresentada a ética cívica como uma alternativa viável que pode contribuir forte e eficazmente para a realização de tal configuração.

\section{Polavras-Chave}

Ética cívica, inclusão, equidade, democracia, participação. 


\section{INTRODUCCIÓN}

¿Qué es el espacio público?, ¿qué se entiende por ciudadanía?, ¿qué papel han jugado estos dos factores o categorías en la historia social de América Latina?, ¿qué es la ética cívica y cómo puede ésta ayudar a reconfigurar las nociones de inclusión social y pluralismo integral ${ }^{1}$ en la región?, son algunos de los interrogantes principales que se propone abordar este escrito. Como se sabe, espacio público alude a "lugar común" o "sitio de todos", y se opone a la categoría de "espacio privado" o "posesión particular"; mientras que ciudadanía hace referencia a la pertenencia e intervención de los individuos en la vida de la polis (o vida en común); con lo que queda claro que ambos factores tienen que ver con la participación política, es decir, con la vida social o ciudadana, la cual implica, fundamentalmente, inclusión. Sin embargo, en la realidad latinoamericana dichas categorías (espacio público y ciudadanía) no han cumplido su papel lógico y natural de aglutinación política; es decir de cohesión social y comunitaria, sino que, por el contrario, se han manifestado como locus de exclusión en todos los órdenes.

Esta situación ha llevado, especialmente en las últimas décadas, a que algunos sectores de la sociedad

latinoamericana (sobre todo académicos e intelectuales), se hayan puesto en la tarea de repensar las categorías de espacio público y ciudadanía con el fin de recuperar su original y auténtica significación, de tal suerte que ello lleve a modificar las concepciones, y por ende las prácticas sociales y ciudadanas inveteradas, que han "privatizado" el espacio público poniéndolo al servicio de unas minorías dominantes y que, además, han excluido de la ciudadanía a un amplio sector de la población (mujeres, originarios, afros, pobres, analfabetas, minorías sexuales, etcétera).

Uno de los intentos más significativos que han permitido repensar la realidad descrita lo constituye la reflexión filosófica sobre el comportamiento moral en la sociedad denominada ética cívica² ${ }^{2}$ En tal sentido, en este artículo se trata el siguiente problema: ¿En qué medida la ética cívica puede ayudar a recuperar el auténtico significado del espacio público y de la ciudadanía en América Latina, de tal manera que todas las personas y grupos, sin distingos de raza, credo, condición social, preferencias sexuales y situación económica, entre otros aspectos, puedan participar de la vida pública y del ejercicio democrático a que tienen derecho aumentando así su nivel de desarrollo humano y de calidad de vida? Más aún, nos preguntaremos con CRAWFORD y FLORES $(2006,229)$ : "¿Cómo construir una noción de derechos democráticos compatible con la diversidad?".

Como se sabe, la ética cívica está asociada a la diversidad cultural, y la diversidad cultural no es nueva:

Es un factor inherente a la ciudad mercantil aparecida a finales del siglo XI y, como tal, un aspecto constitutivo del hecho urbano. Procedentes de los más diversos orígenes, los habitantes de las ciudades de finales de la Edad Media concibieron la ley de la ciudad como el conjunto de normas que, por encima de las diferencias étnicas, religiosas o sociales, creaba un sentido de pertenencia con la ciudad. Así, por ejemplo, la Carta de Arras, en 1194, declaraba que un forastero "después de permanecer libremente y sin oposición durante un año y un día, será burgués y tendrá la ley de la ciudad", lo cual implicó una nueva noción de identidad asociada a lo urbano y una nueva ética que, con el transcurrir de los siglos, denominaríamos ética civil, ya no asociada a factores religiosos o culturales sino al cumplimiento de unas leyes y normas que reglamentaran la convivencia ciudadana y la actividad mercantil. (CRAWFORD y FLORES: 2006, 228).

No obstante, según CRAWFORD y FLORES (2006), esta nueva ética no cobijó por igual a una gran cantidad de individuos y de grupos que quedaron por fuera. La ética civil, derivada de los principios liberales, fue burguesa: blanca, masculina y cristiana. Únicamente a partir de la década de los sesenta del siglo pasado, se fue generando en Europa y Norteamérica una nueva noción de lo público y una ética ciudadana que incluía a todos los grupos de la nación. Para finales del siglo XX, en la mayoría de las ciudades del Primer Mundo se podía constatar, a través de la materialidad de la ciudad, la existencia de niveles mínimos de bienestar para todos sus ciudadanos y se logró que la brecha existente entre los más pobres y los más ricos se redujera ostensiblemente. Mientras tanto, en las ciudades del Tercer Mundo los tradicionales cinturones de miseria crecían aceleradamente y la distancia entre los pobres y los ricos se hacía cada vez más grande.

Se constata así que, "mientras muchas de las democracias del Primer Mundo se esfuerzan por estimular el surgimiento de una ciudadanía multicultural, en América 
Latina apenas se inicia el proceso de promover una noción básica de ciudadanía que permita a los habitantes conocer, reconocer y ejercer los derechos y deberes inherentes a su condición de habitantes de la ciudad" (CRAWFORD y FLORES: 2006, 229). En este proceso, la ética desempeña un papel determinante, pero no solamente la ética cívica, pues, como afirma Alba Carosio, "La ética de la justicia ha de ser completada por una ética del cuidado, basada en la relación amorosa, en la compasión y en la responsabilidad por los otros (...). El cuidado se propone como responsabilidad social y no mera elección individual, como un valor social transformador de la convivencia ${ }^{3}$." (CAROSIO: 2007, 159). La ética está llamada, entonces, a contribuir en el proceso latinoamericano de transformación del espacio público y de la ciudadanía, como se muestra en este escrito.

\section{ESPACIO PÚBLICO: DEFINICIÓN, CONTEXTUALIZACIÓN Y REPERCUSIONES EN LAS TRANSFORMACIONES ACTUALES DE LA SOCIEDAD LATINOAMERICANA}

"Espacio público" es un concepto polisémico: alude a perspectivas diversas y a connotaciones heterogéneas. En efecto, cuando escuchamos esta expresión pensamos en categorías como: "interés común", "utilidad común", "uso común", "lugar de todos" y "espacio libre, visible y abierto a todos". En el espacio público es donde se despliega la ciudadanía y donde la representación política se hace presente. Es donde se da la participación ciudadana, donde se construye la opinión pública y donde se genera e incrementa el capital social. Pero también es el lugar (físico y simbólico) en el que se da la confrontación, el conflicto; es el ámbito en que interactúan la esfera pública, la movilización popular y la ciudadanía. En el espacio público se dan las relaciones sociales, que son relaciones de poder; el poder se manifiesta en el espacio púbico.

Para Olga SEGOVIA el espacio público "tiene dimensiones físicas, sociales, culturales y políticas. Es un lugar de relación y de identificación, de manifestaciones políticas, de contacto entre las gentes, de animación urbana, a veces de expresión comunitaria" (SEGOVIA: 2002, 117). Piensa, además que "el espacio público supone dominio público, uso social colectivo y diversidad de actividades. Se caracteriza físicamente por su accesibilidad, rasgo que lo hace ser un elemento de convergencia" (118). También afirma esta autora que "la calidad del espacio público se podrá evaluar sobre todo por la intensidad y la calidad de las relaciones sociales que facilita, por su capacidad de acoger y mezclar distintos grupos y comportamientos, y por su capacidad de estimular la identificación simbólica, la expresión y la integración cultural" (118-119).

Por su parte, VIVIESCAS (1997), cree que, en tanto escenario de lo cotidiano, el espacio público cumple funciones materiales y tangibles: es el soporte físico de las actividades cuyo fin es satisfacer las necesidades urbanas colectivas que trascienden los límites de los intereses individuales, las cuales cumple desde y dentro de las lógicas económica, social y política y ambientalmente predominantes. Y, además de estas funciones físicas, el espacio público configura el ámbito para el despliegue de la imaginación y la creatividad, el lugar de la fiesta (donde se recupera la comunicación de todos con todos), del símbolo (de la posibilidad de reconocernos a nosotros mismos), del juego, del monumento, de la religión.

Pero al espacio público también se le asignan otras connotaciones. BORJA (1998), por ejemplo, señala que al espacio público se le pide ni más ni menos que contribuya a proporcionar sentido a nuestra vida urbana. En los espacios públicos que se expresa la diversidad, se produce el intercambio y se aprende la tolerancia. La calidad, la multiplicación y la accesibilidad de los espacios públicos definirán en buena medida el progreso de la ciudadanía. Mientras que, JOSEPH (1998), considera al espacio público como un escenario para la acción. Un escenario, en la medida que es un espacio pensado para que en su seno ocurran ciertas cosas, y esas cosas son acciones desarrolladas por los ciudadanos. Considera dos entradas: por un lado el espacio público es un orden de visibilidades destinado a acoger una pluralidad de usos o una pluralidad de perspectivas y que implica, por lo tanto, una profundidad y por el otro el espacio público es un orden de interacciones y de reencuentros y presupone una reciprocidad de perspectivas.

Por otra parte, cuando se habla de "espacio público" es casi que ineludible hacer referencia a su contrario, es decir, a "espacio privado". Y es que, en general, lo público no es posible comprenderlo completamente si no es en alusión a lo privado. En tal sentido, Benjamín TEJERINA realiza la siguiente precisión:

La dicotomía público/privado tiene su correlato en otra dicotomía que funciona como equivalencia entre político y personal (no político). Así, mientras lo público es político no privatizable, ni susceptible 
de apropiación personal (la infracción de esta regla llevaría a la corrupción o apropiación indebida), lo personal es apolítico, no susceptible de publificación colectiva, esfera resguardada de la intromisión del público y de la política (escrutinio público). Lo privado es lo que está fuera del alcance del escrutinio público y de los intentos de visibilización por parte del público: lo opaco de la vida del yo frente a "los otros". Pero es visible para el yo en términos de conciencia de tu forma de vida y de cosas que tú puedes hacer (coherencia personal) y de lucha diaria en tu vida personal (transformación personal). (TEJERINA: Octubre, 2005, 90).

Sin embargo, esta dicotomía no opera como una realidad irreconciliable y contradictoria, pues “(...) lo que sucede en el espacio público tiene una conexión directa con

los espacios de la privacidad, con los intereses privados y con la agregación de estos intereses en redes de socialidad que conectan diversas individualidades. Una especie de privacidad compartida que se hará visible cuando la movilización política ocupe el espacio público" (TEJERINA: Octubre, 2005, 67).

De esta forma, el citado autor, junto al sentido tradicional de la separación entre lo público-político y lo privado-personal, propone nuevos sentidos que posibilitan una comprensión más amplia y equilibrada de ambas realidades, dado que, según sus palabras:

a) (...) lo público no existe sin la participación de lo privado, luego la acción política implica necesariamente "mi" contribución personal;

b)(...) lo político es profundamente personal, puesto que la búsqueda de coherencia personal exige la acción pública (como toma de conciencia de tu forma de vida frente a un problema general);

c) (...) lo político es lo que afecta a lo íntimo y, por lo tanto, sólo la transformación de lo íntimo es auténticamente político (lo que cada uno puede hacer en su vida personal como parte de una lucha diaria).

Estos sentidos inducen a la participación en la movilización social, a la emergencia de nuevos sentidos de la ciudadanía en las condiciones de individualización y producción de la identidad colectiva, características de la sociedad contemporánea, en una constante redefinición de los límites de la esfera pública. (TEJERINA: Octubre, 2005, 95-96).
En síntesis, un análisis detenido de la literatura y autores citados nos lleva a inferir que es necesario revisar y dotar de un nuevo sentido a la categoría espacio público. Esto es válido para cualquier realidad, pero sobre todo para Latinoamérica en donde, como se ha dicho, la desequilibrada situación social y la sistemática exclusión política de vastos sectores de la población han llevado a distorsionar, manipular y anular el auténtico significado de la polis como lugar de participación e inclusión ciudadanas. En tal sentido, los debates teóricos y académicos que se han producido en nuestra región en las últimas décadas, sumados a los movimientos sociales que reivindican a los grupos minoritarios, han contribuido (y siguen contribuyendo) a la transformación de la sociedad en general y de la vida en común, en particular.

\section{CIUDADANÍA: CONCEPTO, NATURALEZA Y NECESIDAD DE REDEFINICIÓN EN PERSPECTIVA LATINOAMERICANA}

¿Qué es la ciudadanía? Este concepto se remonta a la Grecia clásica de mediados del siglo V a.C. y se encuentra fuertemente asociado al rompimiento de los privilegios de la aristocracia ateniense y la apertura de las puertas de la vida pública a personas provenientes de otra condición social. Esta concepción de ciudadanía, -asociada a la noción de democracia-, fue impulsada en Atenas por el partido demócrata, particularmente por Pericles, y se extendió prácticamente hasta el inicio de la Modernidad, en la que pensadores como HOBBES (2009) y SPINOZA (1986) sentaron las bases de la comprensión actual. En efecto, según Francisco Lavolpe:

La noción iniciada por Thomas Hobbes define a los ciudadanos como portadores de derechos que el Estado debe proteger. El "estado civil" o de ciudadanía basado en un contrato social nos diferencia del hombre en "estado natural". Luego, estos derechos modernos incluyen la propiedad, la libertad de expresión, la libre asociación, la libertad de culto, etc. De este modo (según Baruc Spinoza), "llamamos ciudadanos a los hombres que se considera que gozan de todas las ventajas que procura la ciudad en virtud del derecho civil". La condición de ciudadano implica también el respeto al contrato constitutivo de un Estado al que se le cede una parte de la libertad individual. (LAVOLPE: 2008, 55). 
Sin embrago, para LAVOLPE (2008), la noción de ciudadanía hoy enfrenta nuevos retos, pues la realidad mundial ha cambiado. La globalización ha traído, entre otras consecuencias, la necesidad de pensar y de situarse no solo localmente sino también mundialmente: se habla entonces de la categoría "ciudadano global" o "ciudadano del mundo". Pero en contraste con dicha noción, se destaca la aparición de otra categoría, la del "ciudadano marginal" o "protociudadano", "(...) una configuración de roles que replica la polarización entre integrados y marginados en el marco del nuevo orden socioeconómico global y propone nuevos desafíos para la estabilidad política doméstica e internacional" (47). Como es natural, América Latina se haya inserta en este nuevo orden que genera "nuevas exclusiones".

De otra parte, según Marisa REVILLA (Mayo-junio, 2010) la concepción de ciudadanía en América Latina ha devenido ligada a la acción de los movimientos sociales que, en las dos últimas décadas del siglo XX y la primera del siglo XXI, han contribuido a formar ciudadanos más aptos para la participación política y más conscientes de sus reales capacidades para transformar la sociedad. "En efecto - dice esta autora- en general, los movimientos sociales suponen un esfuerzo por ampliar la capacidad de inclusión de la democracia, en el convencimiento de que esas experiencias contribuyen a fortalecer la ciudadanía" (51).

Algunas de las movilizaciones sociales más recientes en América Latina han sido protagonizadas por indígenas, piqueteros, desocupados, pingüinos o cocaleros. Otras han estado asociadas a "cortes de ruta", "caceroladas" o "marchas por la dignidad". Además, son famosos en el pasado levantamientos tales como: las Madres de Plaza de Mayo, el Movimiento de los Trabajadores Sin Tierra (MST), las asociaciones de familiares de detenidos desaparecidos, los comedores populares, las tomas de terreno, los comités de vaso de leche, los movimientos de mujeres y los grupos ecologistas, entre tantas otras movilizaciones (REVILLA: Mayo-junio, 2010). Los trabajos de ESCOBAR, ÁLVAREZ y DAGNINO (2001), demuestran que todas estas movilizaciones están implicadas en las luchas por la demarcación del escenario político, pues aunque en general los movimientos sociales buscan lograr el reconocimiento por parte del sistema político, en estos casos lo que prevalece es la producción de una concepción alternativa de ciudadanía. Lo ocurrido en Latinoamérica muestra que estos movimientos
Mientras muchas de las democracias del Primer Mundo se esfuerzan por estimular el surgimiento de una ciudadanía multicultural, en América Latina apenas se inicia el proceso de promover una noción básica de ciudadanía que permita a los habitantes conocer, reconocer y ejercer los derechos y deberes inherentes a su condición de habitantes de la ciudad. 
sociales están implicados fundamentalmente en "la multiplicación de escenarios públicos en los cuales se pueda cuestionar y volver a dar significado a la exclusión sociocultural, de género, étnica y económica (y no solo a la política)" (ESCOBAR, ÁLVAREZ y DAGNINO: 2001, 42).

En consonancia con las apreciaciones de ESCOBAR, ÁLVAREZ Y DAGNINO, REVILLA concluye que:

Es precisamente la riqueza de las experiencias de la acción colectiva y los movimientos sociales en América Latina lo que puede guiarnos en el rigor y el reconocimiento a los esfuerzos por ampliar la capacidad de inclusión de la democracia, en el convencimiento de que esas experiencias contribuyen a formar una ciudadanía más hábil para la participación política y más consciente de sus capacidades (Mayo-junio, 2010, 67).

En la medida en que los movimientos sociales han contribuido a reformular la noción de ciudadanía y sus implicaciones en la participación política, también han aportado elementos muy valiosos para una nueva comprensión del poder. En tal sentido, vale la pena recor-

dar que, según Aníbal QUIJANO (2001), el poder se caracteriza por ser un tipo de relación social constituido por la co-presencia permanente de tres elementos: dominación, explotación y conflicto.

Quijano sostiene que el poder se manifiesta como un patrón histórico, resultado y expresión de la disputa por el control de las cuatro áreas básicas de la existencia social: el trabajo, el sexo, la autoridad colectiva (o pública) y la subjetividad/intersubjetividad.

El actual patrón de poder mundial consiste en la articulación entre: 1) la colonialidad del poder, esto es la idea de "raza" como fundamento del patrón universal de clasificación social básica y de dominación social; 2) el capitalismo, como patrón universal de explotación social; 3) el Estado como forma central universal de control de la autoridad colectiva y el moderno estado-nación como su variante hegemónica; 4) el eurocentrismo como forma hegemónica de control de la subjetividad/ intersubjetividad, en particular en el modo de producir conocimiento (QUIJANO: 2000, 202).

QUIJANO (Septiembre-diciembre, 1997, 30) advierte que "lo que ahora se llama globalización es, sin duda, un momento del proceso de desarrollo histórico de tal patrón de poder, quizá el de su culminación y de su transición (...)". En todo caso, una comprensión más exacta y profunda de la ciudadanía, exige, sobre todo en América Latina, un examen detenido del mencionado patrón de poder que hoy se impone en todo el mundo y que, según QUIJANO, alcanza su "materialización" en lo que actualmente se conoce como globalización. De hecho, el primer componente del patrón, denominado "colonialidad", ha dado ya lugar a un extenso y enriquecedor debate en nuestra región ${ }^{4}$.

Colonialidad es un concepto diferente, aunque vinculado con el concepto de colonialismo. Este último se refiere estrictamente a una estructura de dominación y explotación, donde el control de la autoridad política, de los recursos de producción y del trabajo de una población determinada lo detenta otra de diferente identidad, y cuyas sedes centrales están, además, en otra jurisdicción territorial. Pero no siempre, ni necesariamente, implica relaciones racistas de poder. El colonialismo es, obviamente, más antiguo, en tanto que la colonialidad ha probado ser, en los últimos 500 años, más profunda y duradera que el colonialismo. Pero sin duda fue engendrada dentro de éste y, más aún, sin él no habría podido ser impuesta en la intersubjetividad del mundo, de modo tan enraizado y prolongado. (QUIJANO: 2007, 93).

Varios autores y autoras se han preocupado por el "pensamiento descolonial" o "giro decolonial". Algunos de los más conocidos y conocidas, -aparte del ya citado Aníbal QUIJANO-, han sido Edgardo LANDER (2000 y 2001), Walter MIGNOLO (2005) y Yuderkys ESPINOSA (Julio/diciembre, 2009). Veamos:

Para LANDER es claro que el eurocentrismo y el colonialismo han estado presentes en el pensamiento social latinoamericano, en efecto,

Las diferentes vertientes principales del pensamiento que ha sido históricamente hegemónico sobre y desde América Latina pueden ser caracterizadas como colonial-eurocéntricas. Existe una continuidad básica desde las Crónicas de Indias, el pensamiento liberal de la independencia, el positivismo y el pensamiento conservador del siglo XIX, la sociología de la modernización, el desarrollismo en sus diversas versiones durante el siglo XX, el neoliberalismo y las disciplinas académicas institucionalizadas en las universidades del continente. 
Más allá de la diversidad de sus orientaciones y de sus variados contextos históricos, es posible identificar en estas corrientes hegemónicas un sustrato colonial que se expresa en la lectura de estas sociedades a partir de la cosmovisión europea, y en su propósito de transformarlas a imagen y semejanza de las sociedades del Norte, que en sucesivos momentos históricos han servido de modelo a imitar. (LANDER: 2000, 210).

Sin embargo, este autor reconoce que se han desarrollado igualmente otras corrientes de pensamiento $y$ otras opciones de conocimiento sobre la realidad del continente, desde los márgenes, en la defensa de formas ancestrales, alternativas, de conocimiento, expresión de la resistencia cultural, o asociadas a luchas políticas y/o procesos de movilización popular: "La descolonización del imaginario y la desuniversalización de las formas coloniales del saber aparecen así como condiciones de toda transformación democrática radical de estas sociedades" (LANDER: 2000, 211).

Walter MIGNOLO, considera, por su parte, que el pensamiento des-colonial "se desprende y se abre (...) a posibilidades en-cubiertas (colonizadas y desprestigiadas como tradicionales, bárbaras, primitivas, místicas, etc.) por la racionalidad moderna montada y encerrada en las categorías del griego y del latín y de las seis lenguas imperiales Europeas modernas" (MIGNOLO: 2005, 6). El planteamiento de este autor es relativamente simple y lógico:

(...) si la colonialidad es constitutiva de la modernidad puesto que la retórica salvacionista de la modernidad presupone la lógica opresiva y condenatoria de la colonialidad (...); esa lógica opresiva produce una energía de descontento, de desconfianza, de desprendimiento entre quienes reaccionan ante la violencia imperial. Esa energía se traduce en proyectos de de-colonialidad que, en última instancias, también son constitutivos de la modernidad. (...) La des-colonialidad es entonces la energía que no se deja manejar por la lógica de la colonialidad ni se cree los cuentos de hadas de la retórica de la modernidad. (MIGNOLO: 2005, 5).

Por último, la escritora Yuderkys ESPINOSA (Julio/ diciembre, 2009), trata el tema de la decolonialidad desde la perspectiva de "estudio de género", y lo sitúa en América Latina ${ }^{5}$. En efecto, para esta autora, la constitución histórica del feminismo latinoamericano se ha dado dentro de contextos postcoloniales de largo alcance. Piensa que los énfasis teóricos y políticos de los feminismos latinoamericanos ideológicamente han dependido de los procesos y discursos del primer mundo, dificultando y obstaculizando así la producción de un pensamiento y una praxis situada. "Esta condición, concluye Espinosa, determina indefectiblemente la sujeta del feminismo de la región, así como los objetivos urgentes de su política" (40). En definitiva, para la citada escritora, el feminismo latinoamericano ha sido un feminismo de colonialidad, por lo cual es necesario "descolonializarlo".

En síntesis, el concepto de ciudadanía, como casi toda la realidad social de América Latina, está preñado de colonialismo y eurocentrismo; es necesario, por lo mismo, cargarlo de un nuevo sentido, un sentido que responda a lo que realmente somos y no a lo que otros han querido que seamos.

\section{ÉTICA CÍVICA: SU PAPEL EN LA CONSTRUCCIÓN Y EXPRESIÓN DEL ESPACIO PÚBLICO Y LA CIUDADANÍA EN AMÉRICA LATINA.}

Lo planteado hasta aquí nos lleva a concluir que en América Latina, tanto el espacio público como la ciudadanía, históricamente se han constituido en factores de exclusión social; sin embargo, en las últimas décadas han surgido movimientos sociales y comportamientos individuales que buscan reivindicar el valor de la ciudadanía y su relación con la institucionalidad política. Estas nuevas tendencias se han centrado en la necesidad de repensar los procesos de participación ciudadana, de inclusión social, de pluralidad étnicocultural y de prácticas auténticamente democráticas. En ese contexto se inscribe la aparición de la ética cívica como una alternativa que aglutina las tendencias descritas y que, por tanto, constituye un interesante aporte a la reconfiguración del espacio público y de la ciudadanía en nuestro continente. ¿Qué es la ética cívica?, ¿cuál es su origen?, ¿cuáles son sus componentes?, ¿de qué se ocupa?, son algunos de los interrogantes que se tratan a continuación

La ética civil o ética de mínimos. Según la filósofa española Adela CORTINA $(1995,8)$, "la ética civil es, en principio, la ética de los ciudadanos, es decir, la 
moral que los ciudadanos de una sociedad pluralista han de encarnar para que en ella sea posible la convivencia pacífica, dentro del respeto y la tolerancia por las concepciones del mundo".

A esta ética civil a veces se le llama "ética laica" para contraponerla a la "ética religiosa", como si el hecho de fe fuera contrario al hecho de razón. En tal caso la ética civil sería una ética racional en tanto que la creencia quedaría en un nivel irracional. Parece, pues, que la ética civil se limita a un conjunto de principios morales para una convivencia pacífica -convivencia democrática- en nuestras sociedades pluralistas independientemente de políticas, de credos religiosos e ideo-

logías. Es la ética de los ciudadanos, que se comprometen a no interferir en los proyectos de vida y en la actuación de los demás ciudadanos -principio de no interferencia-. De este principio emanarían un conjunto de normas que se basan en dos ejes: libertad e igualdad. De ahí surgen, todos los derechos. Tanto es así que algunos piensan que el contenido esencial de la ética civil es la Declaración Universal de los Derechos Humanos. El respeto a tales derechos en relación a las condiciones indispensables para el ejercicio de la libertad, es un deber de justicia exigible a cualquier ciudadano de una sociedad pluralista (SANABRIA: enero-abril, 1998, 9).

CORTINA (1993) cree que existe una relación estrecha entre ética civil y pluralismo. Por lo cual en la ética civil se omite tratar, por ejemplo, de la vida buena porque le parece que la palabra "bueno" pertenece a la religión. Aristóteles creía que la amistad es importante para una vida feliz. La ética civil respeta estos temas pero no se ocupa de ellos porque su campo es lo exigible a todo ciudadano. Y la amistad no se puede exigir a nadie. La ética civil tampoco se atreve a dar juicios sobre los deberes en relación a la propia persona porque sólo le corresponde buscar las condiciones de la convivencia democrática. Por consiguiente, la vida privada se queda en la libertad de cada quién y nada tiene que ver con los demás. Más aún, en los deberes para con los demás no debe ir más allá de la justicia; le basta exigir que nadie cause mal a los demás porque prescribir acciones positivas que excedan lo anterior es estar en un ambiente más bien religioso.
En relación con lo anterior, CORTINA (1993) aclara que la expresa limitación a los deberes de justicia ha llevado a llamar a la ética cívica ética de mínimos -ética mínima ${ }^{6}$ - para no cerrar el paso, al menos explícitamente, a una ética de máximos ${ }^{7}$. La ética civil -llamada también ética cívica- se limita a lo mínimo exigible a cualquier ciudadano en una sociedad pluralista. Se trata de procurar un "mínimo decente", unos mínimos básicos, es decir "condiciones de justicia". Lo demás: la felicidad, el bienestar, etcétera, el ciudadano verá cómo se las arregla para lograrlo. Quede, por ejemplo, para la religión, el fenómeno moral llamado felicidad, siempre que se mantengan universalmente exigibles unos principios básicos, unos deberes innegociables, unos «mínimos decentes» que permitan a los ciudadanos convivir, si no en condiciones de felicidad sí, al menos, en condiciones de justicia. De aquí que hoy es común en ética la distinción entre lo bueno y lo justo, entre lo mínimo y lo máximo: los mínimos de justicia son lo racional y los máximos de bienaventuranza pertenecen a las religiones.

Así se distingue una ética universalista - de mínimosy una ética particularista -de máximos-. Y en unas sociedades pluralistas y multiculturales se ha de buscar, al menos, un consenso máximo en los mínimos, y un acuerdo mínimo en los máximos, tanto más que la moral racional de mínimos es común a todos los humanos. En este sentido un partidario de la ética civil asegura que ella indica el grado de maduración ética de la sociedad, y dice: "La ética civil pretende ser la moral correlativa al estado avanzado de la sociedad democrática del presente. Por lo demás en ella se decanta lo mejor de los paradigmas morales de Occidente» (VIDAL: 1991, 516).

Según CORTINA (1995), no hay oposición entre ética de mínimos y ética de máximos, porque la ética mínima es laica y para orientar el interés personal y comunitario no remite expresamente a Dios, pero tampoco lo niega expresamente. Al reconocer la existencia de ciertos valores mínimos comunes a todos los humanos, los comparte con ellos en un pluralismo no impositivo sino dialogado y argumentado. Por eso, entre los partidarios de una ética de mínimos y los partidarios de la ética de máximos no hay "competencia" alguna. Entre las religiones y la ética cívica no hay contradicción, como se empeñan en mantener laicistas y fideístas, llevados por su afán de entender las relaciones humanas como juegos donde lo que gana el uno lo pierde el otro. Es éste, por el contrario, un “juego" en el que todos pueden cooperar potenciando los mínimos ya 


\section{El concepto de ciudadanía, como casi toda la realidad social de América Latina, está preñado de colonialismo y eurocentrismo; es necesario, por lo mismo, cargarlo de un nuevo sentido, un sentido que responda a lo que realmente somos y no a lo que otros han querido que seamos.}

compartidos, para que "ganemos" los hombres -mujeres y varones- en el camino de la justicia y de la liberación. Lo cual no significa que quienes tengan propuestas de máximos las silencien, sino todo lo contrario, que sigan haciéndolas, pero no desde la imposición, sino desde el lugar apropiado para ofrecer el amor, que es el diálogo y la vivencia personal. Porque así como la universalidad de los mínimos de justicia es una universalidad exigible, la de los máximos de felicidad es una universalidad ofertable.

Como se puede deducir, y dado el pluralismo étnico, cultural, lingüístico, religioso, político, social, etcétera, que caracteriza a América Latina, la ética cívica constituye un interesante proyecto de transformación y de convivencia ciudadanas.

\section{Antecedentes de la ética cívica}

La ética cívica es relativamente joven, nace en la Modernidad y bajo el siguiente lema: Todos los hombres podemos convivir a pesar de nuestras diferencias de credos, razas, condición social y sexual, nacionalidad, ideología, nivel educativo y cultural, entre otros, siempre y cuando tengamos unos valores y unas normas mínimas comúnmente aceptadas. Como se sabe, antes de que surgiera la ética cívica predominaba una ética religiosa (ética de máximos) que partía de la idea de que quien mejor podía poner las bases del comportamiento moral del hombre era Dios. Dios (y no las mujeres y los hombres) era la fuente de la moral. La ética religiosa le apuntaba a dos frentes: al cumplimiento de deberes y virtudes para alcanzar la perfección individual (ética individual), y al cumplimiento de deberes y virtudes en las relaciones sociales (ética social).
En la Modernidad (siglos XVI y XVII) surge el pluralismo social, en virtud de éste ya no se pueden imponer las ideas, las confesiones religiosas ni las verdades; ahora cada cual puede "tomar partido". Este pluralismo se caracteriza por "la unidad dentro de la diversidad". No significa que con él todos puedan hacer lo que les plazca o que todo esté permitido, sino que, una vez acordado un marco de valores aceptado por todos, cada cual puede optar por lo que mejor le parezca para su propia realización. De esta manera, el pluralismo social abona el terreno para el surgimiento del pluralismo moral que, a su vez, posibilita el nacimiento de la ética cívica, la cual se constituye en el marco general para la aparición de las éticas aplicadas (ética médica, ética ecológica y ética de la empresa, entre otras) (HAMBURGER: 2005).

\section{Principales componentes de la éfica cívica}

Según Adela CORTINA (2000), para que una determinada sociedad pueda implementar y desarrollar una ética cívica se necesitan tres componentes, a saber: una ética de mínimos, una ética de ciudadanos y una ética de la modernidad. Veamos qué es lo que afirma la citada autora en cuanto a cada uno de estos tres aspectos.

1) Una ética de mínimos. Hay dos tipos de sociedades: las sociedades totalitarias en las cuales un grupo impone sus criterios (religiosos, ideológicos, morales, etcétera) a la mayoría. Aquí no se permiten las diferencias y quienes piensen distinto del grupo que impone sus normas son discriminados, perse- 
guidos, expulsados y, en algunos casos, eliminados. En estas sociedades se impone una ética de máximos a partir de la cual el grupo que detenta el poder impone un ideal de felicidad a todos los demás grupos. América Latina, por ejemplo, históricamente ha sido una sociedad totalitaria. El otro tipo es el de las sociedades pluralistas. En éstas conviven diversas personas y grupos que se proponen distintas éticas de máximos, pero ninguno intenta imponer su ética a los demás; a lo sumo invitan a compartirla con el diálogo y el testimonio.

2) Una ética de ciudadanos. Es una ética de todos: no de dirigentes y dirigidos, de amos y súbditos; no permite la discriminación o exclusión de personas por razón de condición social, intelectual, económica o cultural. Los derechos y deberes son para todos; la ley no puede ser sólo para "los de ruana"8. De acuerdo con lo presentado en este escrito, en América Latina nunca ha existido una ética de ciudadanos.

En la Modernidad

(siglos XVI y XVII)

surge el pluralismo

social, en virtud de

éste ya no se pueden

imponer las ideas, las

confesiones religiosas

ni las verdades; ahora

cada cual puede "tomar

partido". Este pluralismo

se caracteriza por "la

unidad dentro de la

diversidad".
3) Una ética de la modernidad. La modernidad se caracteriza por el libre pensamiento. Nadie puede imponer a otro sus concepciones. No hay verdades eternas y dogmas ni instituciones que posean la verdad absoluta, a menos que se ganen tal distinción a pulso y a fuerza de arrastrar con el propio ejemplo. En la ética moderna predomina la autonomía lautos= el mismo, nomos= (ey), es decir, cada uno "se dicta su propia ley"; cada uno debe decidir en qué pensar, en quién creer y qué hacer con su vida. Como en los dos casos anteriores, es relativamente fácil colegir que tampoco este tipo de ética se ha dado en nuestro continente.

Como sabemos, el espíritu de la modernidad fue descrito por Emanuel KANT (1987), quien en su texto "¿Qué es la llustración?", afirmó: "Atrévete a servirte de tu propia razón". Esto es lo que se conoce como "la mayoría de edad de la humanidad". En estos postulados encontramos, sin duda alguna, los fundamentos de una nueva sociedad y, por ende, de una nueva ética, la ética cívica.

\section{Contenidos mínimos de la ética cívica}

La ética cívica se estructura sobre unos valores clave de cara a la auténtica comprensión del espacio público y de la ciudadanía en cualquier sociedad del Planeta. En el caso de América Latina estos valores son prioritarios; helos aquí: libertad, igualdad y solidaridad; derechos humanos; tolerancia activa y, diálogo. Veamos (CORTINA: 2000, 39-42):

1) Libertad, igualdad y solidaridad. La ética cívica nace de la convicción de que los seres humanos somos ciudadanos capaces de tomar decisiones de un modo moralmente autónomo, es decir, libre y, por tanto, de tener un conocimiento suficientemente acabado de lo que consideramos bueno y de cómo organizar la convivencia sin necesidad de recurrir a autoridades impuestas.

La igualdad en este contexto significa lograr para todos iguales oportunidades de desarrollar sus capacidades, corrigiendo las desigualdades naturales y sociales, y ausencia de dominación de unas personas por otras, ya que todos son iguales. Recordemos que libertad e igualdad fueron los dos primeros valores que acogió como suyos la Revolución Francesa de 1789, de la que surgió la Declaración de los derechos del hombre y del ciudadano. Estos dos valores, junto con la solidaridad (o fraternidad) constituyen el contenido fundamental de la ética cívica. 
2) Derechos humanos. No son "derechos legales", son "derechos morales" porque aunque fundamentan el derecho positivo, no forman parte de él, sino que pertenecen al ámbito de la moralidad (en éste, contrario a lo que ocurre en el ámbito legal, el incumplimiento de lo que debe ser no viene castigado con sanciones externas al sujeto y prefiguradas legalmente).

3) Tolerancia activa. La tolerancia pasiva es una predisposición a "no meterme en lo que no me importa" por comodidad, por no complicarme la vida. La tolerancia activa, en cambio, es una predisposición a respetar los proyectos ajenos aunque no los comparta.

4) Diálogo. Del griego dia (a través de) y logos (palabra), el diálogo es el mejor modo de conjugar dos posiciones éticas que parecen difíciles de conciliar: el universalismo y el respeto a la diferencia. El respeto a la diferencia es muy importante porque sólo si reconocemos que la autonomía de cada persona tiene que ser universalmente respetada, podremos exigir que se respeten sus peculiaridades, y la forma de hacerlo será a través de diálogos en los que cada uno exprese tales peculiaridades desde la unidad que supone saberse al menos mínimamente entendido y máximamente respetado.

\section{Funciones de la ética cívica}

Los mínimos éticos son los que nos permiten, además de llevar adelante una convivencia enriquecedora, realizar otras dos tareas (CORTINA: 2000):

1) Criticar por inmoral el comportamiento de personas e instituciones que violan tales mínimos, y

2) Diseñar desde un esfuerzo conjunto las instituciones y organizaciones de nuestra sociedad. Porque ¿cómo es posible criticar determinadas actuaciones o crear organizaciones legitimadas socialmente, si no hay convicciones morales compartidas desde las cuales hacerlo?

En efecto, en lo que se refiere a las críticas, es innegable que en la sociedad actual -incluida Latinoamérica, por supuesto-, se producen fuertes críticas de inmoralidad contra determinadas conductas, como puede ser en política la corrupción y el tráfico de influencias; en el mundo empresarial, la adulteración de productos, la publicidad engañosa, la baja calidad; en el mundo financiero, la falta de transparencia, los malos manejos, la falta de compasión por el débil. ¿Qué sentido tiene criticar si partimos de la base de que no hay convicciones morales comunes? ¿No me puede responder aquel a quien critico que esa es mi convicción moral, pero que él tiene otras, igualmente respetables? No parece, pues, que todo sea tan opinable y subjetivo como algunos quieren suponer, sino que sí existen en moral exigencias y valores comunes, sobre la base de los cuales es posible argumentary llegar a acuerdos. (CORTINA: 2000).

Naturalmente, se puede aducir que estas críticas no son morales, sino legales: que un Estado de Derecho se mueve dentro de los límites de un marco legal, y que lo que está prohibido es lo que ese marco de leyes prohíbe. De modo que, aunque los ciudadanos no compartan ninguna convicción moral, no tienen más remedio que atenerse a las leyes que todos han convenido en aceptar, porque, en caso contrario, serán sancionados por la autoridad competente. Si esto fuera cierto, a la hora de tomar decisiones, políticos, empresarios, médicos, docentes y los restantes cuerpos sociales, tendrían bastante con atender a dos frentes normativos, que pondrían límite a conductas deshonestas: el Derecho, es decir, la legalidad vigente, válida para todos, puesto que todos son miembros de un Estado de Derecho, y además, la Religión para los creyentes (CORTINA: 2000).

$Y$, ciertamente, es una convicción bien extendida la de que basta con respetar la legalidad o, en el caso de los creyentes, que es preciso atender a la legalidad, por una parte, y a la Iglesia, por otra. De suerte que las deshonestidades son o un delito jurídico o un pecado. Si esto fuera así, ¿entonces dónde queda la ética? El Derecho y la Religión no bastan para actuar moralmente bien, se necesita ese otro modo de saber práctico que se llama ética.

\section{La ética cívica como expresión de una sociedad pluralista}

Como ya se ha dicho, la ética cívica es la ética propia de las sociedades pluralistas en las que ya no hay "verdades absolutas" y se impone, por tanto, el "derecho a la diferencia", en virtud del cual cada persona puede elegir libremente en quién creer, cómo vivir y qué hacer.

El mundo moderno es pluralista: conviven personas y grupos con diferentes concepciones de hombre y de mundo, distintos ideales, diversas religiones, múltiples ideales políticos, etc. A partir de estas condiciones estas personas o grupos aspiran a organizar sus propias vidas de manera autónoma 
buscando la felicidad personal y el bienestar social. Las sociedades pluralistas son sociedades abiertas: reconocen la mayoría de edad de sus ciudadanos, su capacidad para discernir entre lo bueno y lo malo: el pluralismo social conlleva y exige un pluralismo moral. En las sociedades totalitarias y cerradas, anteriores a las pluralistas, nunca se dio el pluralismo moral, puesto que en éstas:

- Se impone a todos los miembros o "súbditos" una visión de mundo unívoca,

- Se impone un código de comportamiento y deberes único, que se exige a "rajatabla" (quienes no lo cumplen son discriminados, rechazados, coaccionados). (HAMBURGER: 2005, 128).

El que la sociedad actual sea pluralista no implica que sea una sociedad individualista y anarquizada en la que cada quien pueda hacer "lo que le dé la gana" sin tener en cuenta a los demás (esto no sería sociedad sino barbarie). Las sociedades pluralistas exigen un núcleo mínimo de instituciones y valores compartidos

por los socios que la conforman. Estos mínimos no anulan las diferencias, antes bien, las hacen posibles y las potencian. Surge así la propuesta "adeliana" de una ética de mínimos consensuados y compartidos, asumida con carácter normativo como base de la convivencia civilizada. Esto posibilita una sociedad rica en matices y al mismo tiempo unida gracias a un acuerdo mínimo (HAMBURGER: 2005, 2).

Como se explicó anteriormente, la moral mínima es una moral civil o cívica. Es una moral laica o neutra frente a las religiones (no indiferente u hostil frente a ellas). Esta ética cívica es necesaria, pero no suficiente: una vez de acuerdo todos en unos mínimos básicos, cada uno tiene derecho a aspirar a la propia felicidad y perfección por los caminos que ofrecen las religiones e ideologías libremente asumidas. Las morales que sólo se basan en sus ideales religiosos o laicos sin tener en cuenta otras formas de ser y de pensar son morales de máximos (propias de las sociedades totalitarias y cerradas). Cuando en una sociedad se ha constituido una moral mínima o ética cívica, las morales de máximos no son rechazadas o excluidas; por el contrario, son aconsejables: sólo se les pide que (CORTINA: 1986, 45):

- Reconozcan en cada persona su dignidad de fin y que, por lo mismo, nunca puede ser utilizada como medio.

- Acepten la autonomía moral de todas las personas para decidir su propia realización.
- Defiendan el derecho a la igualdad de todos y todas ante la ley y el justo reparto de posibilidades.

- Más allá de la estricta justicia propongan como virtud fundamental la solidaridad entre todos y todas, especialmente la solidaridad con los más débiles y necesitados.

Una moral cívica consensuada necesita poner en marcha "el uso libre de la razón" (KANT: 1987, 56) La moral cívica es una moral racional. Esto implica comunicación y diálogo. El diálogo ético es el método para llegar a construir una moral cívica. Dialogar éticamente significa: "Poner en común los problemas éticos, dar razón con los demás de las conductas que creemos justas, y estar abiertos siempre a la posibilidad de llegar a acuerdos fundamentales que nos permitan solucionar pacíficamente los conflictos". (CORTINA: 1986, 49). Además, dicho método supone poner en marcha lo que HABERMAS (1987) y APEL (1991) llamaron "razón comunicativa o dialógica". Todo ello posibilita la construcción de una "sociedad política democrática": surge así una "democracia participativa y radical".

\section{Las raíces de la ética cívica:}

la ética discursiva o dialógica

Según José SANABRIA (Enero-abril, 1998, 2), la vida actual se ve envuelta en problemas -teóricos y prácticosque llevan a la necesidad de una ética que regule la actividad humana porque el hombre no debe actuar como si lo impulsara "la ley de la selva". Indudablemente, afirma, es verdad lo que dijera KANT (1975) acerca de que hay una disposición moral inscrita en el género humano; ya quedó dicho que las acciones humanas necesariamente son éticas: o son buenas o son malas.

En la antigüedad la ética aristotélica -ética eudemónica9 - tuvo un gran influjo en la cultura. Para el estagirita la felicidad está en la vida virtuosa. La felicidad-afirma- es: "una actividad del alma conforme a la virtud perfecta». Añade que la razón debe dirigir todos los actos humanos y en esto consiste esencialmente la vida virtuosa. Por lo cual el hombre obtiene su perfección a través de la actividad conforme a la virtud. Entonces la vida humana consiste en "vivir según la razón».

La ética aristotélica, corregida por Tomás de Aquino, se transformó en ética cristiana, o ética de las virtudes, fundada teológicamente. Pero 
con el paso del tiempo la ética se alejó del cristianismo y apareció una ética normativa laica -o ética secular-, es decir, opuesta a la ética de las virtudes, una ética independiente de toda referencia a la religión y a Dios. Esto aconteció en la época moderna -siglo XVIII, según algunos- $Y$ fueron surgiendo diferentes éticas: ética utilitarista, ética kantiana, ética hegeliana, ética contractualista de colaboración, ética consecuencialista, ética discursiva, ética de la intención, ética de la responsabilidad solidaria, ética postmoderna -ética light- ética de la compasión, y otras más (SANABRIA: Enero-abril, 1998, 3).

En la cita precedente, José SANABRIA propone una evolución de la ética en cuya más alta escala se encuentra, entre otras, la ética discursiva. ¿Qué es la ética discursiva? Como se sabe, los fundadores de la ética discursiva son Jürgen HABERMAS y Karl Otto APEL. Digamos también que la ética discursiva recibe otros nombres. Se le ha llamado ética dialógica, porque se pretendió que el principio moral es un principio dialógico; ética de la responsabilidad solidaria, porque desemboca en la responsabilidad de Max Weber y en el «socialismo pragmático» que en la solidaridad manifiesta la actitud racional del "logos» humano esencialmente dialógico y, finalmente, ética comunicativa, porque se funda en normas acordes con la teoría de la comunicación. El nombre más común es el de ética discursiva, porque recurre a una racionalidad ya no estratégica sino consensual-comunicativa mediante el uso del lenguaje y de la reflexión a través de la racionalidad discursiva (SANABRIA: Enero-abril, 1998).

HABERMAS (1987) y APEL (1991), parten de una pragmática-formal, de una teoría de la acción comunicativa; proponen una nueva teoría de la racionalidad, una teoría consensual de la verdad y una teoría de la evolución social. Ambos, como se sabe, pretenden actualizar el método trascendental kantiano. De hecho la ética discursiva se halla inscrita en la tradición kantiana.

Al exponer su ética discursiva HABERMAS (1987 y 1991) afirma que la ética kantiana es deontológica, cognitivista, formalista y universalista. Termina sosteniendo que la ética discursiva, como la ética kantiana, es también deontológica, cognitivista, formalista y universalista. Sin embargo, a su ética le agrega un nuevo elemento: se trata de una ética procedimental (SANABRIA: Enero-abril, 1998).

En síntesis, la idea fundamental de HABERMAS (1987 y 1991), con su ética del dis-

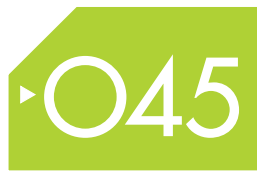
curso, es reformular la teoría moral de Kant en la cuestión de la justificación de las normas mediante la teoría de la acción comunicativa. Por lo mismo las características de la ética kantiana permanecen, de una manera o de otra, en la ética del discurso. Ésta, la ética del discurso, a su vez, entronca con la ética cívica de Adela Cortina, aunque la filósofa no sigue literalmente la doctrina habermasiana y apeliana, sino que aporta elementos propios.

\section{Se distingue una ética universalista - de mínimos- y una ética particularista -de máximos-. Y en unas sociedades pluralistas y multiculturales se ha de buscar, al menos, un consenso máximo en los mínimos, y un acuerdo mínimo en los máximos, tanto más que la moral racional de mínimos es común a todos los humanos.}




\section{CONCLUSIONES}

Llegados a este punto parece válido preguntarse: ¿qué le ofrece la ética cívica a la reflexión moral latinoamericana?, ¿dadas nuestras múltiples problemáticas -entre ellas el espacio público y la ciudadanía-, nos es válido pensar que este tipo de ética puede aportar a la solución de las mismas? En primer lugar, es importante destacar que la sociedad latinoamericana actual posee -al menos formalmente- las características propias de la sociedad pluralista y abierta de inicios del siglo XXI. En tal sentido, nuestra sociedad reclama los componentes y características propios de la ética cívica, a saber: los valores de libertad, igualdad y solidaridad (propios de los derechos humanos), el valor de la tolerancia activa, el diálogo y el testimonio, entre otros. Esto no significa tanto que todas las personas que viven en estas sociedades están de acuerdo en unos valores y derechos, como que las instituciones y organizaciones de tales sociedades cobran su sentido de protegerlos y defenderlos. Por eso las sociedades latinoamericanas han de impregnarse de los mencionados valores, respetar y promocionar los derechos morales, e incorporarlos a su quehacer cotidiano, ya que, en caso contrario, quedan moralmente deslegitimadas. Podemos, pues, decir que precisamente porque la ética de las instituciones cívicas ha alcanzado el nivel descrito, es posible y deseable para nuestra realidad.

Por otra parte, si bien en la vida cotidiana escuchamos críticas constantes a la inmoralidad de todos los sectores de nuestra sociedad (política, prensa, empresa, educación, etcétera) que nos llevan a pensar que, en último término, es imposible ser político, periodista, empresario o educador obrando de manera ética o co-

rrecta, lo cierto es que si ello fuera así, entonces tendríamos que reconocer que es imposible participar en cualquiera de las organizaciones y actividades ciudadanas sin ser inmoral, con lo cual sucedería: a) que la vida humana se asienta sobre la inmoralidad constante, y b) que no habría ninguna ética cívica, porque mal puede haberla si la estructura de todos los sectores sociales los hace necesariamente inmorales. Por eso, si queremos una sociedad alta en moral, es indispensable que los distintos sectores de la sociedad se apresten a re-moralizarla, a poner «en forma» sus peculiares actividades, ya que estamos en el tiempo de las responsabilidades y no sólo de las exigencias (CORTINA: 2000).
No está de más, entonces, que la sociedad latinoamericana haga propios los principio de la ética cívica, a saber: valoración del pluralismo, acogida al universalismo, acatamiento de los derechos humanos, promoción de la comunicación y el diálogo, respeto a la diferencia, búsqueda de la equidad y la honestidad, propensión por una ética de mínimos consensuados, respeto mutuo en las relaciones y tolerancia activa, cumplimiento de las normas acordadas y promoción de la autonomía. La ética cívica, además, puede (y debe) ser complementada por "otras éticas" (sobre todo las de corte regional) como, por ejemplo, la "Ética de la liberación latinoamericana" (DUSSEL: 1998 y 2001), y la "Ética del cuidado" (CAROSIO: 2007), entre otras.

Por último, si por una parte el espacio público y la ciudadanía constituyen el "lugar" por excelencia de la vida política, de la vida en comunidad, y por otra parte la ética cívica es la ética de los ciudadanos, entonces es válido pensar que tanto aquéllos como ésta convergen en un mismo objetivo: la plena realización del hombre como ser social. Además, los lazos comunitarios nacen, se expresan y se fortalecen en principios axiológicos que son propios de la ética cívica, como la solidaridad, la inclusión, la equidad, la participación, el trabajo en equipo, la co-responsabilidad, la compasión, el respeto y la convivencia. Estos principios se hacen más necesarios en las sociedades que históricamente se han caracterizado por ser excluyentes, sectarias, clasistas, racistas y colonialistas, como la latinoamericana. De ahí que la ética cívica sea una "herramienta" que, aunada a otros tipos de ética y a otros mecanismos y procesos sociales, puede contribuir decisivamente en el proceso de construir una mejor sociedad en los aspectos que atañen a la vida en comunidad.

\section{NOTAS}

1 El pluralismo se da en diferentes órdenes sociales: puede hablarse de pluralismo cultural, pluralismo religioso, pluralismo étnico, pluralismo lingüístico, pluralismo ideológico, pluralismo político, etcétera. La expresión "pluralismo integral" se refiere a la realidad que cobija o que aglutina a todos estos pluralismos.

2 A la ética cívica también se la conoce con los nombres de ética civil, ética de mínimos y ética ciudadana.

3 Sobre este tópico véase el apartado "Ética del cuidado y ética de la justicia", en: Alba Carosio (2007), La ética feminista: Más allá de la ética de justicia.

4 Véase, por ejemplo, el trabajo de Santiago Castro-Gómez y Ramón Grosfoguel (eds.) (2007): El giro decolonial: reflexiones para una diversidad epistémica más allá del capitalismo global. 
Desde un estudio de género, y también desde una perspectiva latinoamericana decolonial, véase: "¿Por qué un análisis de género de la globalización?", en: Magdalena Valdivieso (2009), Globalización, género y patrón de poder.

6 La ética de mínimos o ética mínima es una reflexión que se centra en la justicia y pretende precisar qué requisitos básicos debe cumplir cualquier ciudadano en una sociedad pluralista para vivir en armonía con los demás.

7 La ética de máximos aspira al logro de la felicidad, de lo bueno, y pretende ofrecer ideales de vida buena.

8 Expresión colombiana que se usa para designar a las personas que por su precaria condición socio-económica y por su escaso nivel educativo no tienen acceso a las instancias de poder y de decisión (gente común y corriente que no tiene el mismo trato ante la justicia que los ricos e influyentes).

9 Ética eudemónica (ética aristotélica), es la ética que afirma que la felicidad está en la vida virtuosa. La vida virtuosa consiste esencialmente en que la razón dirija todos los actos humanos. Por eso la vida humana consiste en "vivir según la razón".

\section{REFERENCIAS}

- APEL, K. O. (1991). Teoría de la verdad y Ética de la Responsabilidad. Barcelona: Paidós.

- BORJA, J. (1998). "Ciudadanía y Espacio Público". En: Ciutat real, ciutat ideal Significant $i$.

- CAROSIO, A. (2007). "La ética feminista: Más allá de la justicia". En: Revista Venezolana de Estudios de la Mujer [online]. 12 (28), 159-184. Citado el 10 de agosto de 2013, de: http://www.scielo. org.ve/scielo.php?script=sci_arttext\&pid.

- CASTRO-GÓMEZ, S. y GROSFOGUEL, R. (Edits.). (2007). El giro decolonial: reflexiones para una diversidad epistémica más allá del capitalismo global. Bogotá: Siglo del Hombre Editores.

- CORTINA, A. (1986). Ética mínima. Madrid: Tecnos.

- CORTINA, A. (1993). Ética aplicada y democracia radical. Madrid: Tecnos.

- CORTINA, A. (1995). Ética civil y religión. Madrid: PPC.

- CORTinA, A. (2000). Ética de la empresa. Claves para una nueva cultura empresarial. Madrid: Trotta.

- CRAWFORD, L. y FLORES, P. (2006). "América Latina: la ciudad negada", en: Investigación y Desarrollo 14 (1), 226-239.

- DUSSEL, E. (1998). Ética de la liberación en la edad de la globalización y la exclusión. Madrid: Trotta.

- DUSSEL, E. (2001). Hacia una filosofía política crítica. Bilbao: Desclée de Brouwer.

- escobar, A., Álvarez, S. y DAgnino, E. (eds.) (2001). "Introducción: lo cultural y lo político en los movimientos sociales latinoamericanos", En: Política cultural y cultura política. Una nueva mirada sobre los movimientos sociales latinoamericanos, Bogotá: Taurus / ICANH.

- ESPINOSA, Y. (Julio/diciembre, 2009). "Etnocentrismo y colonialidad en los feminismos latinoamericanos: complicidades y consolidación de las hegemonías feministas en el espacio transnacional", en: Revista venezolana de estudios de la mujer, 14 (33) 37-54.

- HABERMAS, J. (1987). Teoría de la acción comunicativa. Madrid: Taurus.

- HABERMAS, J. (1991). Escritos sobre moralidad y eticidad (Trad. M. Jiménez Redondo). Barcelona, Buenos Aires, México: Paidós, 1991.
- hamburger, Á. (2005). Ética de la empresa. El desafío de la nueva cultura empresarial. Bogotá: Paulinas.

- HOBBES, T. (2009). Del Leviatán ola materia, forma y poder de un Estado eclesiástico y civil. $1^{\text {a }}$ ed. Madrid: Alianza Editorial.

- JOSEPH, I. (1998). La ville sans qualités. París: De l'aube.

- KANT, E. (1975). Fundamentación de la metafísica de las costumbres. México: Porrúa.

- KANT, E. (1987). ¿Qué es la llustración? Madrid: Tecnos.

- LANDER, E. (Comp.) (2000). La colonialidad del saber: eurocentrismo y ciencias sociales. Perspectivas latinoamericanas. Buenos Aires: CLACSO.

- LANDER, E. (2001). "Pensamiento crítico latinoamericano: la impugnación del eurocentrismo", en: Revista de Sociología, 15. Santiago de Chile: Universidad de Chile, Departamento de Sociología.

- LAVOLPE, F. (2008). "Las nuevas ciudadanías de la globalización". En: Hologramática, Facultad de ciencias sociales UNLZ. 8 (6), 47-65. Citado el 11 de agosto de 2013 de: http://www. cienciared.com.ar/ra/doc.php? $\mathrm{n}=866$

- MignOLO, W. (2005). "El pensamiento des-colonial, desprendimiento y apertura: un manifiesto", en: Tristestópicos. Citado el 15 de agosto de 2013 de: www.tristestopicos.org

- QuiJANO, A. (2000). "Colonialidad del Poder, Eurocentrismo y América Latina", en: Edgardo Lander (Comp.). Colonialidad del Saber, Eurocentrismo y Ciencias Sociales. pp. 201-246. Buenos Aires: CLACSO-UNESCO.

- QuiJano, A. (2001). "Poder y Derechos Humanos", en: Poder, salud mental y derechos humanos. Lima, Perú: Cecosam.

- QUIJANO, A. (2007). "Colonialidad del poder y clasificación social", en: Santiago Castro- Gómez y Ramón Grosfoguel (edit.). El giro decolonial: reflexiones para una diversidad epistémica más allá del capitalismo global. pp. 93-126. Bogotá: Siglo del Hombre Editores.

- QuiJano, A. (Septiembre-diciembre de 1997). "¿El fin de cuál Historia?", en: Análisis político, Revista del Instituto de Estudios Políticos y Relaciones Internacionales (32) 27-32, Bogotá: Universidad Nacional de Colombia.

- REVILLA, M. (Mayo-junio de 2010). "América Latina y los movimientos sociales: el presente de la rebelión del coro", en: Nueva Sociedad (227) 51-67.

- SANABRIA, J. (enero-abril, 1998). "Una mirada a la ética en este fin de milenio" en Revista de filosofía (91) 3-29. Plantel México: Departamento de Filosofía de la Universidad Iberoamericana.

- SEgOVIA, O. (2002). "Espacio público y ciudadanía: una mirada de género", en: Ana Falú (edit.), Ciudades para varones y mujeres. Herramientas para la acción, p.p.115-135. Buenos Aires: UNIFEM.

- SpINOZA, B. (1986). Tratado Político. Madrid: Alianza Editorial. TEJERINA, B. (Octubre, 2005). "Movimientos sociales, espacio público y ciudadanía: Los caminos de la utopía", en: Revista Crítica de Ciências Sociais (72), 67-97.

- VALDIVIESO, M. (2009). "Globalización, género y patrón de poder", En: Alicia GIRÓN (Coord.), Género y globalización, pp.27-52, $1^{\text {a }}$ ed. Buenos Aires: Consejo Latinoamericano de Ciencias Sociales -CLACSO.

- VIDAL, M. (1991). "La moral cristiana hoy", en Iglesia Viva (155) 510-527.

- VIVIESCAS, F. (1997). “Espacio Público: Imaginación y planeación urbana" En: La calle, lo ajeno, lo público y lo imaginado. Bogotá: Documentos Barrio Taller, Serie Ciudad y Hábitat. 